toria de Luís Amores, Melanie Matos, Miguel Sousa e Paulo Caldeira, sob orientação da professora Dina Albino e ainda "Análise elementar por via seca" da autoria de Afonso Gomes, Diogo Duarte, Luís Rodrigues e Vasco Ferreira, também sob orientação da professora Dina Albino. Todos os vídeos a concurso podem ser consultados em www.spq.pt/gqj/ ou www. youtube.com/user/jovensquimicos.

A Escola vencedora - Escola Secundária Francisco de Holanda, Guima- rães - foi premiada com um cabaz de material didático e de laboratório, cedido pelas empresas que patrocinaram o ChemRus - Porto Editora, Universidade de Aveiro, Paralab, Videq, Laborspirit, Industrial Laborum, Normax, ILC e José Manuel Gomes dos Santos. Agradecemos a excelente adesão que esta iniciativa teve por parte da indústria química. A cerimónia de entrega do prémio decorreu no dia 16 de maio de 2012, na escola secundária vencedora, onde a direção do GQJ foi gentilmente recebida.
Esperamos que o sucesso desta iniciativa possa ser reafirmado em edições futuras!

Vânia Calisto, Sérgio Santos

e Mariana Sardo (gqj@spq.pt)

Grupo de Químicos Jovens

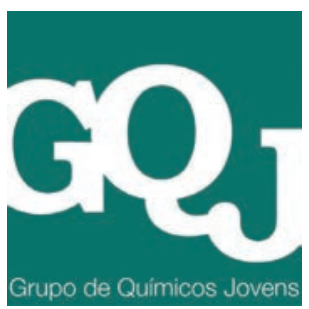

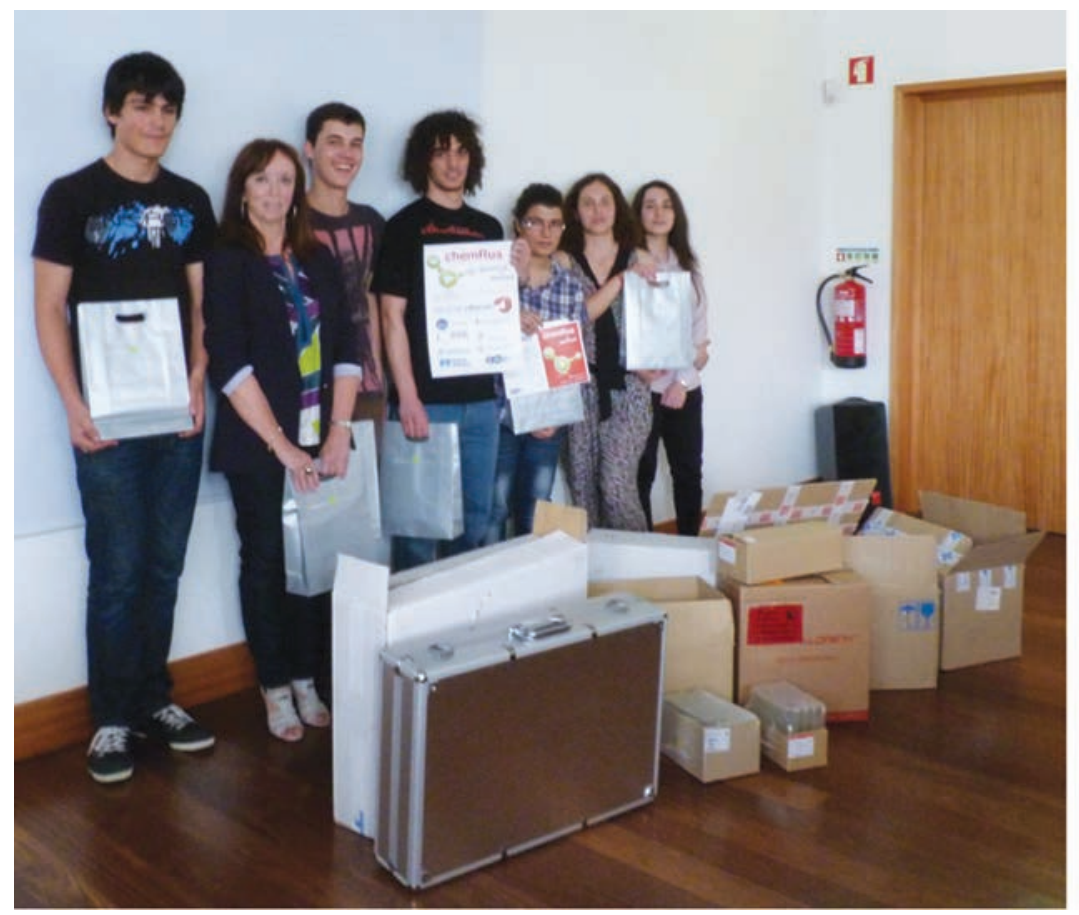

\section{chemRus}

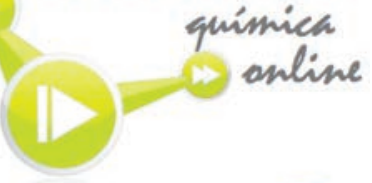

Industrial laborum
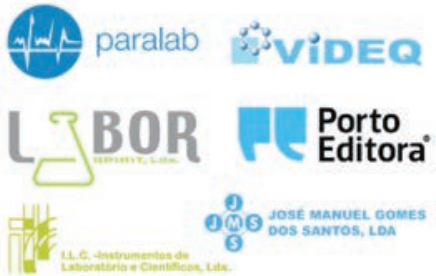

வNORNA正

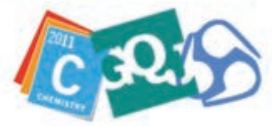

Alunos e professora da Escola Secundária Francisco de Holanda, Guimarães, vencedores da primeira edição do concurso ChemRus - Química Online”

\title{
Divisão de Química Alimentar - Divulgação de Notícias da FCD-EuCheMS
}

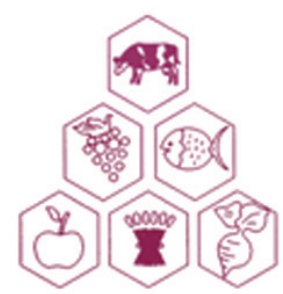

Sendo a SPQ membro da EuCheMS (European Association for Chemical and Molecular Sciences) e estando representada na Food Chemistry Division (FCD) da referida associação, foi recentemente criado um novo ende- reço de e-mail (dqalim@spq.pt) com o objetivo de proceder à divulgação de notícias da FCD-EuCheMS, bem como contribuir para um contacto de maior proximidade com os sócios.

Considerando que o contacto de e-mail de diversos sócios membros da Divisão de Química Alimentar da SPQ, fornecido aquando da sua inscrição na $S P Q$, se encontra desatualizado, todos os interessados em receber as referidas mensagens deverão proceder à atualização do seu contacto através do envio de uma mensagem para dqalim@spq.pt. Mais informações sobre a FCD-EuCheMS podem ser consultadas na página web http://www.euchems.eu/divisions/food-chemistry.html.

Todas as sugestões para fomentar a divulgação de informação/interação entre os sócios da Divisão de Química Alimentar são bem-vindas!

Joana Amaral (dqalim@spq.pt) Presidente da Divisão de Química Alimentar 